\title{
Prophylactic Mastectomy in BRCA1/2 Mutation Carriers and Women at Risk of Hereditary Breast Cancer: Long-Term Experiences at the Rotterdam Family Cancer Clinic
}

\author{
Bernadette A. M. Heemskerk-Gerritsen, ${ }^{1}$ Cecile T. M. Brekelmans, ${ }^{1}$ \\ Marian B. E. Menke-Pluymers, ${ }^{2}$ Albert N. van Geel, ${ }^{2}$ \\ Madeleine M. A. Tilanus-Linthorst, ${ }^{2}$ Carina C. M. Bartels, ${ }^{2}$ Murly Tan, ${ }^{3}$ \\ Hanne E. J. Meijers-Heijboer, ${ }^{4,5}$ Jan G. M. Klijn, ${ }^{1}$ and Caroline Seynaeve ${ }^{1}$
}

\begin{abstract}
${ }^{1}$ Department of Medical Oncology, Family Cancer Clinic, Erasmus MC_-Daniel den Hoed Cancer Center, Rotterdam, The Netherlands ${ }^{2}$ Department of Surgical Oncology, Family Cancer Clinic, Erasmus MC — Daniel den Hoed Cancer Center, Rotterdam, The Netherlands ${ }^{3}$ Department of Psychosocial Care, Family Cancer Clinic, Erasmus MC - Daniel den Hoed Cancer Center, Rotterdam, The Netherlands ${ }^{4}$ Department of Clinical Genetics, Erasmus MC — Daniel den Hoed Cancer Center, Rotterdam, The Netherlands ${ }^{5}$ Department of Clinical Genetics, Vrije Universiteit MC, Amsterdam, The Netherlands
\end{abstract}

\footnotetext{
Received November 17, 2006; accepted April 16, 2007; published online: May 31, 2007.

Address correspondence and reprint requests to: Caroline Seynaeve; E-mail: c.seynaeve@erasmusmc.nl

Published by Springer Science+Business Media, LLC $\odot 2007$ The Society of Surgical Oncology, Inc.
}

\begin{abstract}
( mastectomy $(\mathrm{PM})$ results in the greatest $\mathrm{BC}$ risk reduction. Long-term data on the efficacy and

Methods: From 358 high-risk women (including 236 BRCA1/2 carriers) undergoing PM between 1994 and 2004, relevant data on the occurrence of BC in relation to PM, compliimaging examination results were extracted from the medical records, and analyzed separately

Results: No primary BCs occurred after PM (median follow-up 4.5 years). In one previously unaffected woman, metastatic BC was detected almost 4 years after PM (primary BC not more frequently were $50 \%$ risk carriers $(P<.001)$. Unexpected (pre)malignant changes at PM were found in $3 \%$ of the patients (in 5 affected, and 5 unaffected women, respectively). In complications, leading to 153 surgical interventions $(71 \%)$. Complications were mainly related

Conclusions: The risk of developing a primary BC after PM remains low after longer follow-up. Preoperative imaging and careful histological examination is warranted because of struction mainly concerns cosmetic issues.
\end{abstract}

Key Words: BRCA1/2-Breast cancer-Mastectomy-Prevention-Complications-Unexpected carcinomas. 
Options to reduce this risk are regular surveillance, chemoprevention, or prophylactic surgery. Prophylactic surgery includes prophylactic mastectomy (PM) and/or prophylactic bilateral salpingo-oophorectomy (PBSO). PM implies either a bilateral prophylactic mastectomy (BPM) in high-risk unaffected women as well as in high-risk women with a history of breast cancer (BC) previously treated with breast conserving therapy $(\mathrm{BCT})$, or a contralateral prophylactic mastectomy (CPM) after a unilateral therapeutic mastectomy. Several studies have shown that PM strongly reduces the risk of developing (contralateral) breast cancer, while PBSO reduces the risk of ovarian as well as primary breast cancer. ${ }^{5-10}$ These strategies therefore have commonly been accepted at this moment as risk-reducing strategies for women being at increased risk of $\mathrm{HB}(\mathrm{O}) \mathrm{C}$.

$\mathrm{PM}$, however, is a drastic and irreversible intervention, and in case of breast reconstruction (BR), is accompanied by a substantial complication rate. ${ }^{11}$ Further issues of concern with respect to PM include changes in a woman's body image and self-esteem, changes of sexual function, and in psychological distress.

At the Rotterdam Family Cancer Clinic, 35-51\% of women carrying a BRCA1 or BRCA2 mutation opt for either bilateral or contralateral PM. ${ }^{12,13}$ For women who are contemplating this intervention, it is imperative to have reliable data on the outcomes of PM in a well-defined cohort to make a good informed decision and to minimize postoperative feelings of deception. At the Rotterdam Family Cancer Clinic there is ample and long-term experience with sufficient numbers of women undergoing PM. We previously reported data concerning the occurrence of breast cancer after BPM in unaffected women with a proven BRCA1/2 mutation, ${ }^{5,14}$ complications of PM with breast reconstruction, ${ }^{11,15}$ and psychological aspects of PM in combination with $\mathrm{BR}^{16}$

In the current analysis, we report on an extended series with longer follow-up of women having undergone a PM at the Rotterdam Family Cancer Clinic because of either a proven BRCA1/2 mutation or a genetic susceptibility (50\% risk carriers from a $\mathrm{HB}(\mathrm{O}) \mathrm{C}$ family). Our study sample was large enough to discriminate between unaffected women and women with a history of BC (affected). Special attention is paid to the prevalence of (pre)malignant lesions in prophylactically removed mastectomy specimens. Further, we report on the postoperative complications of PM in combination with breast reconstruction.

\section{PATIENTS AND METHODS}

As of the start of the Rotterdam Family Cancer Clinic in 1991, PM and/or PBSO are being discussed as risk-reducing strategies with women at increased risk of hereditary $\mathrm{BC}$ and/or ovarian cancer. In early years, PM was discussed with BRCA1/2 mutation carriers as well as with women from a $\mathrm{HB}(\mathrm{O}) \mathrm{C}$ family without a proven mutation (so-called 50\% risk carriers), and applied for unaffected as well as affected (with a history of breast cancer) women. Due to the development of more advanced mutation-detection methods enabling the performance of a complete gene mutation screen, there has been a shift in more recent years to discuss the option of PM only with identified mutation carriers. Before 1996, the decision to undergo a PM and/or PBSO was discussed individually by the doctor and the woman in question. As of 1996, women opting for either PM and/or PBSO are additionally discussed in the multidisciplinary Committee on Hereditary Tumors. For this purpose, institutional guidelines concerning the surveillance schedule and indications regarding PM/PBSO have been further elaborated and implemented as of 2000 , which were updated as knowledge progressed and more evidence-based data became available.

Before 2000, no additional examinations were performed before PM, irrespective of the individual situation (unaffected/affected; mutation/50\% risk carrier). Women were seen biannually for physical examination, while a mammography was performed annually. As of 2000, institutional guidelines from the working party on hereditary tumors recommended to perform clinical breast examination (CBE) and imaging examination within 3 months prior to $\mathrm{PM}$, to minimize the risk of finding unexpected malignant changes at PM. At first, imaging examination consisted of either mammography or magnetic resonance imaging (MRI) scan, while more recently MRI has been preferred. Breast ultrasound (US) and, if necessary, fine-needle aspiration cytology (FNAC) are additionally performed in case lesions are found at $\mathrm{CBE}$ or one of the imaging examinations. Further, the guidelines recommend the discussion of the case in the multidisciplinary Committee on Hereditary Tumors and a standard visit with a psychologist. For affected women, the guidelines are extended with dissemination investigations to rule out recurrent or distant breast cancer activity (chest x-ray, liver ultrasound, bone scan, liver functions and determination of $\mathrm{Ca} 15.3 / \mathrm{Ca} 125)$. Where women with a history of ovarian cancer were previously eligible for $\mathrm{PM}$, at the moment this is not discussed anymore in 
this setting, because the prognosis is mainly dictated by the ovarian cancer. In the sample, these women were classified as "unaffected," unless they also had a history of BC.

To evaluate the short-term and long-term medical effects of prophylactic surgery in high-risk women, a combined retrospective and prospective, longitudinal study was activated at our institution, including all genetically susceptible women who had opted for prophylactic surgery (either PM and/or PBSO). Women were informed by oral and written information and were asked for written consent. The protocol was approved by the institutional review board (project EMC-DDHK 98-15).

\section{Surgical Technique}

At our institute, the oncological and plastic surgeon perform the PM and BR as a team. During the operation, the patient is under general anesthesia in a half-supine position. A skin-sparing mastectomy is performed through a vertical, peri-areolar incision, which extends from just above the nipple down the submammary fold. The breast tissue, including the superficial fascia (creating thin skin flaps), the axillary tail, the inframammary fold, the nipple-areolar complex, and the fascia of the pectoral muscle are removed. In case of immediate breast reconstruction, either a subpectoral silicone implant is inserted in a pocket created below the pectoral muscles in a onestage procedure, or autologeous tissue is used. Autologeous reconstruction encompasses a broad range of procedures incorporating the patient's own tissues to recreate the breast. The transverse rectus abdomis myocutaneous (TRAM) flap and latissimus dorsi flap are two standard myocutaneous flaps used for breast reconstruction. More recent modifications to the traditional techniques led to the use of the deep inferior epigastric perforator (DIEP) flap. Nipple reconstruction is offered after 6 months and consists of three small transposition flaps; the areola is mimicked by tattooing the desired skin color. Breast reconstruction is not always performed in the same operation as the mastectomy; the techniques for these delayed reconstructions, however, are as described previously.

\section{Microscopic Examination of Mastectomy Specimens}

As of 1995, a standard procedure has been followed for meticulous microscopic examination of prophylactically removed mastectomy specimens to rule out the presence of "occult" (microscopic) malignant alterations. The protocol prescribes that mastectomy specimens are cut into slices of $0.5-1 \mathrm{~cm}$ thickness, whereby each slice is carefully inspected and palpated for abnormalities. Standard, three randomly selected parenchymal tissue samples from each quadrant and a transverse section through the nipple are submitted for histology, in addition to samples of all visible or palpable abnormalities. Further, three samples from each quadrant of the mastectomy specimens are snap frozen for the tissue bank. Radiographic examination of breast tissue specimens is not performed on a routine basis.

\section{Study Design}

The current study included all women at increased risk of hereditary $\mathrm{BC}$, according to previously described criteria, ${ }^{17}$ who underwent prophylactic bilateral or contralateral mastectomy between January 1, 1994 until December 31, 2004. Of our study cohort 310 women $(86.6 \%)$ underwent PM at our clinic, while 48 women (13.4\%) were treated elsewhere, e.g., due to a waiting list at our clinic, or the fact that previous surgery was performed elsewhere. The latter women were only eligible for this analysis if the follow-up after PM took place at our clinic, and a copy of the pathology report was available. In general, DNA testing was performed before the prophylactic surgery, although some women choose for prophylactic surgery without or irrespective of DNA testing. DNA analysis was performed according to standard procedures, as has been previously described. ${ }^{18,19}$ DNA testing was not an inclusion criterion for participation in the study. Proven noncarriers from a family BRCA mutation were excluded from the study.

Relevant data were extracted from the hospital records. For each woman, including deceased women, the following information was obtained: date of birth, death, and PM, performance (yes/no) and type of breast reconstruction, PBSO, diagnosis of breast and/or ovarian cancer, mutation status, duration of follow-up after PM (end date being either the date of death or the date of last clinic visit in case of loss to follow-up, or the end date of this study, i.e. December 31,2004 ), and type and number of complications after breast reconstruction. Regarding the latter, we distinguished between early (within 6 weeks) and late postoperative complications (after 6 weeks). Early complications consisted of infection, necrosis, bleeding, and luxation of the prosthesis. Late complications were divided in surgical complications (such as capsular formation, infection, necrosis, and luxation 
TABLE 1. Characteristics of the study population

\begin{tabular}{|c|c|c|c|c|c|c|c|c|c|}
\hline \multirow[t]{3}{*}{ HISTORY OF BC } & \multicolumn{4}{|c|}{ No (Unaffected, $n=177$ ) } & \multicolumn{4}{|c|}{ Yes (Affected, $n=181$ ) } & \multirow[b]{3}{*}{$P$ value } \\
\hline & \multicolumn{2}{|l|}{ BRCA } & \multicolumn{2}{|c|}{$\mathrm{HB}(\mathrm{O}) \mathrm{C}$} & \multicolumn{2}{|l|}{ BRCA } & \multicolumn{2}{|c|}{$\mathrm{HB}(\mathrm{O}) \mathrm{C}$} & \\
\hline & $n$ & $(\%)^{a}$ & $n$ & $(\%)^{a}$ & $n$ & $(\%)^{a}$ & $n$ & $(\%)^{a}$ & \\
\hline No. of women $(N)$ & 145 & $(82)^{b}$ & 32 & $(18)^{b}$ & 91 & $(50)^{c}$ & 90 & $(50)^{c}$ & $<.001^{e}$ \\
\hline Death due to cancer & 0 & $(0)$ & 1 & (3) & 9 & (10) & 7 & (8) & \\
\hline \multicolumn{10}{|l|}{ Age at PM (years) } \\
\hline Median & 36.0 & & 38.5 & & 42.0 & & 47.0 & & $<.001$ \\
\hline Range & $22-65$ & & $28-55$ & & $25-65$ & & $26-68$ & & \\
\hline$<30$ years & 18 & (12) & 3 & (9) & 6 & (7) & 2 & (2) & $<.001$ \\
\hline $30-39$ years & 74 & (51) & 14 & (44) & 26 & (29) & 22 & (24) & \\
\hline $40-49$ years & 36 & $(25)$ & 10 & (31) & 38 & (42) & 31 & (34) & \\
\hline$\geq 50$ years & 17 & (12) & 5 & (16) & 21 & (23) & 35 & (39) & \\
\hline Duration of follow-up (years) & 4.4 & & 4.7 & & 3.9 & & 4.5 & & \\
\hline \multicolumn{10}{|l|}{ Mutation status } \\
\hline BRCA1 & 115 & (79) & - & & 76 & (84) & _ & & \\
\hline BRCA2 & 30 & (21) & - & & 15 & (16) & - & & \\
\hline \multicolumn{10}{|l|}{ PBSO } \\
\hline Yes & 83 & $(57)$ & 3 & (9) & 61 & (67) & 12 & (13) & .13 \\
\hline No & 62 & (43) & 29 & (91) & 30 & (33) & 78 & (87) & \\
\hline \multicolumn{10}{|l|}{ Age at PBSO (years) } \\
\hline Median & 40.0 & & 45.0 & & 43.0 & & 49.0 & & $<.01$ \\
\hline Range & $29-57$ & & $35-45$ & & $32-65$ & & $37-58$ & & \\
\hline \multicolumn{10}{|l|}{ Timing of PBSO } \\
\hline Before PM & 18 & $(22)$ & 2 & $(67)$ & 14 & $(23)$ & 6 & $(50)$ & .11 \\
\hline At PM & 35 & $(42)$ & 1 & (33) & 16 & (26) & 5 & $(42)$ & \\
\hline After PM & 30 & (36) & 0 & (0) & 31 & (51) & 1 & (8) & \\
\hline Ovarian cancer before PM & 4 & (3) & 0 & $(0)$ & 2 & (2) & 1 & (1) & \\
\hline Unexpected (p)MF at PM & 3 & (2) & 2 & (6) & 4 & (4) & 1 & (1) & \\
\hline \multicolumn{10}{|l|}{ Cancer after PM } \\
\hline Breast cancer & 1 & (1) & 0 & $(0)$ & 0 & $(0)$ & 0 & (0) & \\
\hline Ovarian cancer & 2 & (1) & 0 & (0) & 1 & (1) & 0 & $(0)$ & \\
\hline
\end{tabular}

$\mathrm{BC}$, breast cancer; $\mathrm{HB}(\mathrm{O}) \mathrm{C}$, hereditary breast(/ovarian) cancer; PM, prophylactic mastectomy; PBSO, prophylactic bilateral salpingooophorectomy; (p)MF, (pre)malignant findings.

${ }^{a}$ Percentage of the number of women in column in question, unless stated otherwise.

${ }^{\mathrm{b}}$ Percentage of unaffected women.

${ }^{c}$ Percentage of affected women.

${ }^{\mathrm{d}}$ Difference between unaffected and affected BRCA1/2 mutation carriers, unless stated otherwise.

${ }^{\mathrm{e}}$ Difference in distribution between unaffected and affected women.

of the prosthesis), and complaints related to cosmetic outcome (such as poor symmetry and dog ears). Nipple reconstruction is regarded as part of the breast reconstruction and therefore has not been registered as a cosmetic complication. A computerized database (MS-Access) was used to process the data. Data were entered retrospectively as well as prospectively after each clinic visit.

\section{Statistical Analysis}

Descriptive statistics (median, range, and frequency) were computed. When appropriate, statistical significance testing between relevant subgroups was performed using the chi-square test for categorical variables and a $t$-test for continuous variables. A $P$ value of less then .05 was considered statistically significant.

\section{RESULTS}

\section{Study Population}

In Table 1 the characteristics of the women who underwent a PM are shown. A total of 358 women, with a median follow-up after PM of 4.5 years, fulfilled the study eligibility criteria, consisting of 181 $(50.6 \%)$ women with a history of breast cancer (affected women), and 177 (49.4\%) women without a history of BC (unaffected women). A total of 236 (65.9\%) women were BRCA1/2 mutation carriers, while the other 122 women $(34.1 \%)$ were $50 \%$ risk carriers from a $\mathrm{HB}(\mathrm{O}) \mathrm{C}$ family. The unaffected group mainly consisted of BRCA1/2 mutation carriers as compared with $50 \%$ risk carriers $(82 \%$ vs $18 \%, P<$ .001 ), whereas the affected group consisted of an equal number of mutation carriers and 50\% risk 
TABLE 2. Comparison between unaffected and affected women

\begin{tabular}{llll}
\hline & Unaffected & Affected & $P$ value \\
\hline $\begin{array}{l}\text { No. of women }(N) \\
\text { Age at PM (years) }\end{array}$ & $177(\%)$ & $181(\%)$ & \\
$\quad$ Median & 37 & 44 & $<.001$ \\
Range & $22-65$ & $25-68$ & \\
$\quad<30$ years & $21(12)$ & $8(4)$ & $<.001$ \\
30-39 years & $88(50)$ & $48(27)$ & \\
40-49 years & $46(26)$ & $69(38)$ & \\
$\geq 50$ years & $22(12)$ & $56(31)$ & \\
PBSO & $86(49)$ & $73(40)$ & .12 \\
Yes & $91(51)$ & $108(60)$ & \\
No & & & \\
Age at PBSO (years) & 40 & 44 & $<.001$ \\
Median & $29-57$ & $32-65$ & \\
Range &
\end{tabular}

PM, prophylactic mastectomy; $\mathrm{PBSO}$, prophylactic bilateral salpingo-oophorectomy.

carriers (91 mutation carriers versus $9050 \%$ risk carriers, $P=.94)$. This difference in distribution was highly significant $(P<.001)$.

The median age at PM in the unaffected and affected group was significantly different, being 37 and 44 years, respectively (Table $2, P<.001$ ). In the affected group, mutation carriers were significantly younger at PM than 50\% risk women (42 vs 47 years, respectively; $P=.045)$. In the unaffected group, we found no significant difference in this respect (36 vs 38.5 years, respectively; $P=.102$ ). A history of ovarian cancer was present in four mutation carriers from the unaffected group (2.3\%), and in three women $(1.7 \%)$ in the affected group.

In Fig. 1, the number of PMs per year, separately for unaffected/affected BRCA mutation carriers, as well as for unaffected/affected $50 \%$ risk carriers is shown. In the unaffected group, the annual number of women undergoing PM was always larger in mutation carriers compared with 50\% risk carriers, except for the first 2 years (1994/1995). Further, the number of unaffected BRCA mutation carriers undergoing PM widely differed over the years, with two peaks in 1998 and 2001, respectively. In contrast, the number of unaffected $50 \%$ risk carriers undergoing PM was quite stable over the years.

In the affected group, however, the pattern was different, whereby a shift has taken place through the years. In the early years of the study period (19941997), mainly women without a proven mutation underwent PM in this group. Between 1997 and 2001, approximately as many mutation carriers as $50 \%$ risk carriers underwent a PM. As of 2002, more mutation carriers have undergone a PM, although the number of PMs in 2004 again was not different between mutation and $50 \%$ risk carriers.

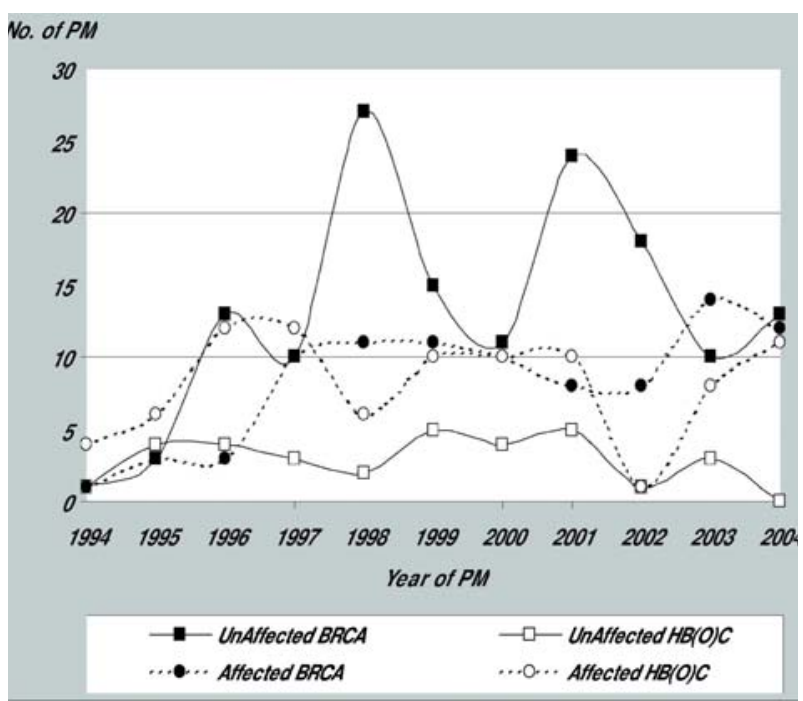

FIG. 1. Annual number of PM in unaffected/affected BRCAa/2 mutation carriers and $0 \%$ risk carriers from $\mathrm{HB}(\mathrm{O}) \mathrm{C}$ families.

\section{Prophylactic Bilateral Salpingo-oophorectomy}

A considerable part of the BRCA mutation carriers undergoing PM also opted for PBSO, being 57\% in the unaffected versus $67 \%$ in the affected group, respectively (Table $1, P=.13$ ). In the $\mathrm{HB}(\mathrm{O}) \mathrm{C}$ group, however, only a minority of the women underwent a PBSO, being 15 of $12250 \%$ risk carriers $(12 \%)$. The median age at PBSO was younger in BRCA mutation carriers compared with the $50 \%$ risk carriers, both in the affected and the unaffected group. This difference, however, was not significant $(P=.13$ and $P=.40$, respectively). Further, the median age at PBSO was lower in the unaffected compared with the affected group, being 40 versus 44 years, respectively (Table $2, P<.001$ ). In addition, unaffected BRCA mutation carriers underwent PBSO at a younger age compared with mutation carriers with a history of BC (40 vs 43 years, respectively, $P<.01$, Table 1 ).

\section{(Pre)malignant Findings at PM}

In 10 of the 358 women (2.8\%), abnormal findings were unexpectedly found in the mastectomy specimens (table 1). Prior to intended PM there was no suspicion to justify an axillary nodal dissection in combination with the PM procedure. This occurred in five "unaffected" $(2.8 \%)$ as well as in five previously affected women $(2.8 \%)$, and in both mutation carriers $(3 \%)$ and $50 \%$ risk carriers $(2.5 \%)$. 
TABLE 3. Characteristics of unexpected (pre)malignant findings in the PM specimens

\begin{tabular}{|c|c|c|c|c|c|c|c|c|c|c|}
\hline \multirow[b]{2}{*}{ Year of PM } & \multirow{2}{*}{$\begin{array}{l}\text { Genetic risk } \\
\text { group }\end{array}$} & \multirow{2}{*}{$\begin{array}{l}\text { History of BC } \\
\text { before PM }\end{array}$} & \multirow[b]{2}{*}{ Histology } & \multirow[b]{2}{*}{ Grade } & \multirow[b]{2}{*}{ Tumor size (mm) } & \multirow[b]{2}{*}{ ER/PR status } & \multicolumn{3}{|c|}{ Preoperative } & \\
\hline & & & & & & & $\mathrm{CBE}$ & $\mathrm{Mx}$ & \multicolumn{2}{|l|}{ MRI } \\
\hline 1995 & $\mathrm{HB}(\mathrm{O}) \mathrm{C}$ & No & IDC & NA & NA & NA & $\mathrm{SC}$ & $\mathrm{SC}$ & & $a, b$ \\
\hline 1996 & $\mathrm{HB}(\mathrm{O}) \mathrm{C}$ & No & DCIS & II & $<2$ & NA & PB & $\mathrm{nl}$ & & $\mathrm{a}$ \\
\hline 1996 & BRCA1 & No & LCIS & NA & NA & NA & $\mathrm{nl}$ & $\mathrm{nl}$ & & \\
\hline 1997 & $\mathrm{HB}(\mathrm{O}) \mathrm{C}$ & Yes & DCIS & I & NA & NA & $\mathrm{nl}$ & & & $\mathrm{c}$ \\
\hline 1997 & BRCA1 & Yes & DCIS & II & $<2$ & NA & $\mathrm{nl}$ & PB & & $\mathrm{a}$ \\
\hline 1997 & BRCA1 & Yes & IDC & II & 3 & Negative & $\mathrm{nl}$ & & & $\mathrm{c}$ \\
\hline 1998 & BRCA1 & Yes & DCIS & NA & $<2$ & NA & $\mathrm{nl}$ & $\mathrm{nl}$ & & \\
\hline 2000 & BRCA1 & Yes & LCIS & NA & NA & NA & $\mathrm{nl}$ & $\mathrm{nl}$ & & \\
\hline \multirow[t]{2}{*}{2002} & BRCA1 & No & IDC & III & 5 & Negative & $\mathrm{nl}$ & $\mathrm{nl}$ & PB & $\mathrm{a}$ \\
\hline & & & IMC & III & 6 & Positive & & & & \\
\hline 2003 & BRCA2 & No & DCIS & II & $<2$ & NA & $\mathrm{nl}$ & $\mathrm{nl}$ & & \\
\hline
\end{tabular}

PM, prophylactic mastectomy; BC, breast cancer; DCIS, ductal carcinoma in situ; LCIS, lobular carcinoma in situ; IDC, invasive ductal carcinoma; IMC, invasive medullar carcinoma; CBE, clinical breast examination; Mx, mammography; MRI, magnetic resonance imaging; $\mathrm{SC}$, suspicion of cancer; $\mathrm{PB}$, probably benign; nl, normal; NA, not applicable.

${ }_{b}^{a}$ Additional investigation normal.

${ }^{b}$ Macroscopic palpable tumor; microscopic no clear border, therefore tumor size and grade not determinable.

${ }^{\mathrm{c}}$ Treated previously for $\mathrm{BC}$ at another hospital. No information about preoperative imaging available.

The characteristics of the unexpected (pre)malignant findings as well as the preoperative screening results are chronologically described in detail in Table 3. In 1995, in one woman both preoperative clinical breast examination (CBE) and mammography were suspicious for a malignancy. However, additional investigation, consisting of ultrasound and cytology, did not reveal a malignancy. Nevertheless, histological examination of the mastectomy specimens revealed an invasive ductal carcinoma (IDC), eventually staged as a $\mathrm{pT}_{x} \mathrm{~N}_{1} \mathrm{M}_{\mathrm{o}}$. The patient died of metastatic breast cancer 4 years after the PM. In another two women, undergoing PM in 1996 and 1997, a lesion was found preoperatively (CBE and mammography, respectively) and classified as probably benign. No malignant abnormalities were seen at subsequent ultrasound examination, which is the reason a FNAC was not performed. However, histological examination of the mastectomy specimens revealed a small ductal carcinoma in situ (DCIS) in both women. In 2002, in one woman preoperative MRI revealed a lesion classified as probably benign. Indeed, no malignant abnormalities were found at additional ultrasound examination. Histological examination of the mastectomy specimens, however, revealed an IDC in the right, and an invasive medullar carcinoma (IMC) in the left breast. Preoperative screening in the remaining six women, performed 1-6 months preceding PM, did not show suspicious abnormalities. Still, another invasive carcinoma, three cases of DCIS, and two cases of lobular carcinoma in situ (LCIS) were found in the mastectomy specimens. All unexpected (pre)malignant findings in the affected women were found in the contralateral breast.

\section{Cancer During Follow-up After PM}

After PM, no incident breast cancer cases were observed in $50 \%$ risk carriers.

In BRCA mutation carriers, ovarian cancer was detected in two women in the unaffected group, and in one woman in the affected group (Table 1).

One BRCA1 mutation carrier from the unaffected group presented in 2001, 3.5 years after PM (no malignant findings at histological examination), with metastatic adenocarcinoma in an axillary lymph node, morphologically and immunohistochemically consistent with breast cancer. Additional dissemination examinations also revealed metastases in bone and liver. Review of the preoperative data (physical examination and mammography) at the presentation of metastatic disease did not show malignant alterations, while meticulous reexamination of all pathology slides and additional investigation of frozen tissue material did not detect a primary breast cancer.

\section{Reconstructive Breast Surgery}

In Table 4, the numbers and types of reconstructive breast surgery, as well as the numbers and types of complications after breast reconstruction (BR) are shown. Of the total population $(n=358)$, 276 women underwent BR in combination with PM, 
TABLE 4. Breast reconstruction (BR) in women undergoing PM

\begin{tabular}{|c|c|c|c|c|c|}
\hline \multirow{2}{*}{$\begin{array}{l}\text { History of BC } \\
\text { Number of women }\end{array}$} & \multicolumn{2}{|c|}{ No (Unaffected) } & \multicolumn{2}{|c|}{ Yes (Affected) } & \multirow[b]{2}{*}{$P$ value } \\
\hline & 177 & $(\%)$ & 181 & $(\%)$ & \\
\hline \multicolumn{6}{|l|}{ Breast reconstruction (BR) } \\
\hline No & 9 & (5) & 68 & (37) & \multirow[t]{3}{*}{$<.001$} \\
\hline Yes & 166 & (94) & 110 & (61) & \\
\hline Unknown $^{a}$ & 2 & (1) & 3 & $(2)$ & \\
\hline \multicolumn{6}{|l|}{ Type of BR } \\
\hline Silicon prosthesis & 159 & (96) & 95 & $(86)$ & \multirow[t]{3}{*}{.004} \\
\hline Autologeous tissue & 6 & (3) & 14 & (13) & \\
\hline Unknown $^{a}$ & 1 & (1) & 1 & (1) & \\
\hline \multicolumn{6}{|l|}{ Therapy first $\mathrm{BC}^{b}$} \\
\hline $\mathrm{BCT}$ & - & - & 7 & (6) & \\
\hline $\mathrm{BCT} / \mathrm{RT}$ & - & - & 33 & (30) & \\
\hline MAST & _- & _- & 67 & (67) & \\
\hline MAST/RT & - & - & 3 & (3) & \\
\hline \multicolumn{6}{|l|}{ Women with complications after BR } \\
\hline No & 84 & $(51)$ & 55 & $(50)$ & \multirow[t]{2}{*}{.92} \\
\hline Yes & 82 & (49) & 55 & $(50)$ & \\
\hline Total number of complications after $\mathrm{BR}^{c}$ & 127 & & 88 & & \\
\hline Early (<6 weeks after BR) & 42 & (33) & 31 & (35) & .74 \\
\hline Late ( $>6$ weeks after BR) & 85 & $(67)$ & 57 & $(65)$ & \\
\hline \multicolumn{6}{|l|}{ Surgery due to late complication } \\
\hline No & 38 & $(30)$ & 24 & (27) & \multirow[t]{2}{*}{.67} \\
\hline Yes & 89 & (70) & 64 & (73) & \\
\hline \multicolumn{6}{|l|}{ Early complications } \\
\hline \multicolumn{6}{|l|}{ Surgery due to early complication } \\
\hline No & 27 & $(64)$ & 17 & $(55)$ & \multirow[t]{2}{*}{.42} \\
\hline Yes & 15 & (36) & 14 & (45) & \\
\hline \multicolumn{6}{|l|}{ Type of early complication } \\
\hline Infection & 8 & (19) & 14 & $(45)$ & \multirow[t]{6}{*}{.09} \\
\hline Necrosis & 11 & (26) & 4 & (13) & \\
\hline Bleeding & 20 & $(48)$ & 12 & (39) & \\
\hline Prosthesis luxation & 2 & (5) & 0 & (0) & \\
\hline Poor arterial inflow & 0 & $(0)$ & 1 & (3) & \\
\hline Pneumothorax & 1 & (2) & 0 & $(0)$ & \\
\hline \multicolumn{6}{|l|}{ Late complications } \\
\hline \multicolumn{6}{|l|}{ Surgery due to late complication } \\
\hline No & 11 & (13) & 7 & (12) & \multirow[t]{2}{*}{.91} \\
\hline Yes & 74 & (87) & 50 & $(88)$ & \\
\hline \multicolumn{6}{|l|}{ Type of late complication } \\
\hline Infection & 4 & (4) & 0 & $(0)$ & \multirow[t]{6}{*}{.33} \\
\hline Necrosis & 1 & (1) & 3 & (5) & \\
\hline Capsular formation & 31 & (37) & 20 & (35) & \\
\hline Prosthesis luxation & 2 & (2) & 3 & $(5)$ & \\
\hline Poor cosmetic appearance ${ }^{d}$ & 31 & (37) & 19 & (34) & \\
\hline Dog ear & 16 & (19) & 12 & (21) & \\
\hline
\end{tabular}

$\mathrm{PM}$, prophylactic mastectomy; $\mathrm{BC}$, breast cancer; $\mathrm{BR}$, breast reconstruction; $\mathrm{BCT}$, breast conserving therapy; $\mathrm{BCT} / \mathrm{RT}, \mathrm{BCT}$ in combination with radiotherapy; MAST, therapeutic mastectomy; MAST/RT, MAST in combination with radiotherapy.

${ }^{a}$ Surgery performed at another hospital, not included in $P$ value calculation.

${ }^{b}$ Data shown for women with a BR after PM.

${ }^{c}$ One woman can have $\geq 1$ complication.

${ }^{d}$ Including asymmetry.

being $60 \%$ unaffected and $40 \%$ affected women. The presence or absence of a BRCA1/2 mutation did not influence the BR rate $(P=.23$ for unaffected, and $P$ $=.10$ for affected women), or the type of BR $(P=$ .25 for unaffected, and $P=.68$ for affected women). Unaffected women mainly opted for BR (94\%), consisting of 163 immediate and three delayed reconstructions, while a considerable part of the affected women did not opt for BR (37\%)
$(P<.001)$. Further, unaffected women mainly opted for BR by means of (silicon) prosthesis $(96 \%)$. In contrast, affected women opting for BR (102 immediate, and 8 delayed) more often had a reconstruction by means of autologeous tissue compared with unaffected women, being $13 \%$ versus $3 \%$, respectively $(P=.004)$.

In 137 of 276 women opting for BR (49.6\%) one or more complications were registered, totaling 215 
complications. Surgical reinterventions were performed in 153 cases (124 for late complications).

Concerning the number of complications, this was not different between unaffected and affected women, neither for the moment of the complication (i.e., early or late) $(P=.74)$, the necessity of reintervention due to the complication $(P=.67)$, nor for the type of complication $(P=.09$ for early complications and $P=.33$ for late complications).

\section{DISCUSSION}

In this study we updated and extended the longterm experiences at the Rotterdam Family Cancer Clinic with prophylactic mastectomy (PM) in proven BRCA1/2 mutation carriers and in 50\% risk carriers from a $\mathrm{HB}(\mathrm{O}) \mathrm{C}$ family. We compared the data of PM and breast reconstruction (if performed) in women with (affected) and without a personal history of BC (unaffected women) and further distinguished between women with a BRCA 1 or 2 mutation, and women without a proven mutation. While within the unaffected group, especially BRCA1/2 mutation carriers opted for PM, we observed that within the affected group an equal number of mutation carriers and $50 \%$ risk carriers from a $\mathrm{HB}(\mathrm{O}) \mathrm{C}$ family opted for PM. Women carrying a BRCA 1 or 2 mutation are known to have an increased risk of developing contralateral primary $\mathrm{BC},{ }^{20,21}$ which is even more apparent among women who are younger when diagnosed with a primary breast carcinoma (age $<50$ years). ${ }^{22,23}$ For high-risk women without a proven mutation inconsistent results on the risk of developing a contralateral breast cancer (CBC) were reported. Shahedi et al. ${ }^{24}$ as well as Kirova et al. ${ }^{25}$ reported an increased risk of developing $\mathrm{CBC}$ in nonBRCA1/2 women, while Tilanus et al. ${ }^{26}$ concluded that the rate of $\mathrm{CBC}$ was only slightly and insignificantly increased in non-BRCA $1 / 2$ compared with sporadic breast cancer patients. In view of these results, one expects that after a first diagnosis of breast cancer, especially mutation carriers will opt for prophylactic removal of the remaining breast tissue. In our study sample, however, also a considerable part of the women without a proven BRCA1/2 mutation opts for prophylactic mastectomy, especially after a history of breast cancer. It has to be mentioned that, since information on the BRCA1/2 mutation status is not always known in the latter group and genetic testing is missing a number of mutations, it is likely that some of these patients are in fact mutation carriers. Further, the group of women with a history of breast cancer, with and without a gene mutation, may partly consist of women who initially chose for surveillance, and eventually opted for PM after the diagnosis of breast cancer. This is in accordance with an earlier report indicating that women may be more likely to undergo PM after a previous diagnosis of BC. ${ }^{27}$ This might also partly explain the higher age at the time of PM in the group with a history of BC.

We found that the age at PM was younger in unaffected women, both for mutation carriers as for $50 \%$ risk carriers. Further, we found a significant difference between unaffected and affected mutation carriers in the distribution of the numbers of PM over the various age categories, with the highest numbers of PM in the age group of 30-40 for unaffected and 40-50 for affected carriers, respectively. Moreover, the distribution of PM over the various age categories remained completely identical to the age distribution reported in a previous study on PM from our institute, ${ }^{5}$ indicating consistency over time.

Our data show that, despite preoperative (imaging) examination, the presence of unexpected microscopic (pre)malignant findings in this group of high-risk women is real (3\%). Other studies reporting on highrisk and/or pathologic findings in prophylactically removed breast tissues, described percentages varying from $0.1-57 \% .^{8,27-29}$ However, the comparison of frequencies of unexpected (pre)malignant findings between studies is hampered by differences in population selection, preoperative screening methods, pathological examination of the specimens, and definition of what is considered (pre)malignant [e.g., lobular carcinoma in situ (LCIS)]. The percentage of unexpected invasive carcinomas in these studies ranged from $0.1-7.7 \%$ ( $0.8 \%$ in our study). Most of these studies, however, did not provide information about the outcome of preoperative physical breast or imaging examination, which at the moment is a standard procedure at our institution. It might be that since the implementation of institutional guidelines concerning preoperative breast examination in 2000, and the introduction of magnetic resonance imaging (MRI), being more sensitive in detecting carcinomas in high-risk women, ${ }^{30,31}$ as detection tool, the number of unexpected malignant findings in the $\mathrm{PM}$ specimens is decreasing.

With a $3 \%$ incidence of unexpected microscopic (pre)malignant findings, the potential role of sentinel node biopsy (SN) for all patients undergoing PM has been discussed. However, the majority of the (pre)malignant findings we found in this series, represents DCIS/LCIS; settings for which a sentinel node biopsy is not standardly indicated. Invasive 
cancer was found in only $0.8 \%$ of the patients in this series. Therefore, in our opinion, routine use of $\mathrm{SN}$ in all patients undergoing PM is not warranted, which is also supported in the paper by Boughey et al. ${ }^{32}$

A previous study from our institution, investigating the efficacy of PM in unaffected women with a proven BRCA1/2 mutation, observed no cases of breast cancer after PM. ${ }^{5}$ The mean follow-up in that study was 3 years. In the current cohort, one BRCA1 mutation carrier presented with metastatic disease 3.5 years after PM (no primary BC found), suggesting the presence of an occult primary tumor that was never found, despite a thorough reexamination of the specimen at the presentation of the metastatic disease. This finding emphasizes the fact that despite thorough examination of the mastectomy specimens, the presence of an occult breast cancer cannot be ruled out completely and indicates that a form of surveillance after PM might be relevant.

The number of reconstructions after risk-reducing mastectomy was lower in the affected group. This may be due to the fact that BR after previous radiotherapy and/or therapeutic mastectomy not always leads to satisfactory cosmetic results. ${ }^{15,33}$ Some patients abandon, in consultation with and/or at the advice of their (oncological/plastic) surgeon, from $\mathrm{BR}$ for this reason. Other women have accepted the mutilation/alteration of body image caused by mastectomy, are reluctant to undergo renewed surgery, and prefer the use of external prosthesis.

During the follow-up period of this study, $49.6 \%$ of the women with immediate or delayed BR after PM showed complications. In total 215 complications were registered, leading to surgical reintervention in 153 cases. These findings are consistent with several other reports, ${ }^{34,35}$ though there are also studies reporting lower, ${ }^{11,15,33}$ or even higher ${ }^{36}$ complication rates after (immediate) BR. However, the literature in this area is difficult to compare, in part because not all previous series compare bilateral prophylactic mastectomy in unaffected women with risk-reducing mastectomies in women after a previous therapy for breast cancer. Furthermore, data may not be comparable because of different definitions of complications. Moreover, some studies describe the complication rate as a percentage of the total number of reconstructions, ${ }^{11,15,33}$ while others, like our study, present the percentage of women with complications. ${ }^{34-36}$

We found no differences in the numbers of complications after (immediate) breast reconstruction in unaffected women compared with previously affected women in this study. This finding appears to be in contrast with earlier reports (also from our institution) describing the occurrence of more complications after mastectomy followed by (immediate) breast reconstruction in affected women. These studies report negative effects of preoperative radiotherapy on the cosmetic outcome of the reconstruction, in particular the risk of capsular formation would be increased, having negative consequences on the symmetry of the breasts. Further, asymmetry can be expected to occur more often after previous therapeutic mastectomy. Although we have no explanation for our findings, it is possible that the experience of the surgeons at our institution is important. Indeed, where previously BR by means of silicon prosthesis after breast conserving therapy was performed, this is not done anymore.

In summary, we confirmed our previous findings that prophylactic mastectomy strongly reduces the risk of developing breast cancer in both BRCA1/2 mutation carriers and 50\% risk carriers. As the frequency of unexpected cancers in this high-risk group remains real, preoperative imaging and careful histological examination is warranted. Further, we found a substantial complication rate after breast reconstruction, which mainly concerned late cosmetic issues, almost always leading to additional surgery. In this respect, patients should be informed preoperatively that an optimal cosmetic effect cannot unconditionally be achieved in just one single operation. Concerning the complication rate after BR, we did not find a significant difference between affected and unaffected women. In our opinion, our data are providing additional data on this issue and may help to inform women considering prophylactic mastectomy and their physicians, in the complex process of decision-making.

\section{REFERENCES}

1. King MC, Marks JH, Mandell JB. Breast and ovarian cancer risks due to inherited mutations in BRCA1 and BRCA2. Science 2003; 302:643-6.

2. Ford D, Easton DF, Stratton M, et al. Genetic heterogeneity and penetrance analysis of the BRCA1 and BRCA2 genes in breast cancer families. Am J Hum Genet 1998; 62:676-89.

3. Struewing JP, Hartge P, Wacholder S, et al. The risk of cancer associated with specific mutations of BRCA1 and BRCA2 among Ashkenazi Jews. $N$ Engl J Med 1997; 336:1401-8.

4. Bergfeldt K, Rydh B, Granath F, Gronberg H, Thalib L, Adami HO, Hall P. Risk of ovarian cancer in breast-cancer patients with a family history of breast or ovarian cancer: a population-based cohort study. Lancet 2002; 360:891-4.

5. Meijers-Heijboer H, van Geel B, Van Putten WL, et al. Breast cancer after prophylactic bilateral mastectomy in women with a BRCA1 or BRCA2 mutation. N Engl J Med 2001; 345:159164. 
6. Rebbeck TR, Friebel T, Lynch HT, et al. Bilateral prophylactic mastectomy reduces breast cancer risk in BRCA1 and BRCA2 mutation carriers: the PROSE Study Group. J Clin Oncol 2004; $22: 1055-62$.

7. Hartmann LC, Sellers TA, Schaid DJ, et al. Efficacy of bilateral prophylactic mastectomy in BRCA1 and BRCA2 gene mutation carriers. $J$ Natl Cancer Inst 2001; 93:1633-7.

8. Hartmann LC, Schaid DJ, Woods JE, et al. Efficacy of bilateral prophylactic mastectomy in women with a family history of breast cancer. N Engl J Med 1999; 340:77-84.

9. Meeuwissen PA, Seynaeve C, Brekelmans CT, Meijers-Heijboer HJ, Klijn JG, Burger CW. Outcome of surveillance and prophylactic salpingo-oophorectomy in asymptomatic women at high risk for ovarian cancer. Gynecol Oncol 2005; 97:476-82.

10. Rosen B, Kwon J, Fung Kee FM, Gagliardi A, Chambers A. Systematic review of management options for women with a hereditary predisposition to ovarian cancer. Gynecol Oncol 2004; 93:280-6.

11. van Geel AN, Contant CM, Tjong Joe Wai R, Schmitz PI, Eggermont AM, Menke-Pluijmers MM. Mastectomy by inverted drip incision and immediate reconstruction: data from 510 cases. Ann Surg Oncol 2003; 10:389-95.

12. Meijers-Heijboer EJ, Verhoog LC, Brekelmans CT, et al. Presymptomatic DNA testing and prophylactic surgery in families with a BRCA1 or BRCA2 mutation. Lancet 2000; 355:2015-20.

13. Meijers-Heijboer H, Brekelmans CT, Menke-Pluymers M, et al. Use of genetic testing and prophylactic mastectomy and oophorectomy in women with breast or ovarian cancer from families with a BRCA1 or BRCA2 mutation. $J$ Clin Oncol 2003; 21:1675-81.

14. Klijn JGM, van Geel B, Meijers-Heijboer H, et al. Results of the extended series on prophylactic mastectomy versus surveillance in BRCA1/2 mutation carriers in Rotterdam. Breast Cancer Res Treat 2004; 88[S10]. Ref Type: Abstract.

15. Contant CM, Menke-Pluijmers MB, Seynaeve C, et al. Clinical experience of prophylactic mastectomy followed by immediate breast reconstruction in women at hereditary risk of breast cancer $(\mathrm{HB}(\mathrm{O}) \mathrm{C})$ or a proven BRCA1 and BRCA2 germ-line mutation. Eur J Surg Oncol 2002; 28:627-32.

16. Bresser PJ, Seynaeve C, Van Gool AR, et al. Satisfaction with prophylactic mastectomy and breast reconstruction in genetically predisposed women. Plast Reconstr Surg 2006; 117:167582.

17. Verhoog LC, van den Ouweland AM, Berns E, et al. Large regional differences in the frequency of distinct BRCA1/ BRCA2 mutations in 517 Dutch breast and/or ovarian cancer families. Eur J Cancer 2001; 37:2082-90.

18. Verhoog LC, Brekelmans CT, Seynaeve C, et al. Survival and tumour characteristics of breast-cancer patients with germline mutations of BRCA1. Lancet 1998; 351:316-21.

19. Verhoog LC, Brekelmans CT, Seynaeve C, et al. Survival in hereditary breast cancer associated with germline mutations of BRCA2. J Clin Oncol 1999; 17:3396-3402.

20. Ford D, Easton DF, Bishop DT, Narod SA, Goldgar DE. Risks of cancer in BRCA1-mutation carriers. Breast Cancer Linkage Consortium. Lancet 1994; 343:692-5.

21. Metcalfe K, Lynch HT, Ghadirian P, et al. Contralateral breast cancer in BRCA1 and BRCA2 mutation carriers. $J$ Clin Oncol 2004; 22:2328-35.
22. Robson M, Gilewski T, Haas B, et al. BRCA-associated breast cancer in young women. J Clin Oncol 1998; 16:1642-9.

23. Verhoog LC, Brekelmans CT, Seynaeve C, Meijers-Heijboer EJ, Klijn JG. Contralateral breast cancer risk is influenced by the age at onset in BRCA1-associated breast cancer. $\mathrm{Br} J$ Cancer 2000; 83:384-6.

24. Shahedi K, Emanuelsson M, Wiklund F, Gronberg H. High risk of contralateral breast carcinoma in women with hereditary/familial non-BRCA1/BRCA2 breast carcinoma. Cancer 2006; 106:1237-42.

25. Kirova YM, Stoppa-Lyonnet D, Savignoni A, Sigal-Zafrani B, Fabre N, Fourquet A. Risk of breast cancer recurrence and contralateral breast cancer in relation to BRCA1 and BRCA2 mutation status following breast-conserving surgery and radiotherapy. Eur J Cancer 2005; 41:2304-11.

26. Tilanus-Linthorst MM, Bartels KC, Alves C, et al. Selection bias influences reported contralateral breast cancer incidence and survival in high risk non-BRCA1/2 patients. Breast Cancer Res Treat 2006; 95:117-23.

27. Scott CI, Iorgulescu DG, Thorne HJ, Henderson MA, Phillips KA. Clinical, pathological and genetic features of women at high familial risk of breast cancer undergoing prophylactic mastectomy. Clin Genet 2003; 64:111-21.

28. Khurana KK, Loosmann A, Numann PJ, Khan SA. Prophylactic mastectomy: pathologic findings in high-risk patients. Arch Pathol Lab Med 2000; 124:378-81.

29. Hoogerbrugge N, Bult P, Widt-Levert LM, et al. High prevalence of premalignant lesions in prophylactically removed breasts from women at hereditary risk for breast cancer. J Clin Oncol 2003; 21:41-5.

30. Kriege M, Brekelmans CT, Boetes C, et al. Efficacy of MRI and mammography for breast-cancer screening in women with a familial or genetic predisposition. $N$ Engl $J$ Med 2004; 351:427-37.

31. Kuhl CK, Schrading S, Leutner CC, et al. Mammography, breast ultrasound, and magnetic resonance imaging for surveillance of women at high familial risk for breast cancer. $J$ Clin Oncol 2005; 23:8469-76.

32. Boughey JC, Khakpour N, Meric-Bernstam F, et al. Selective use of sentinel lymph node surgery during prophylactic mastectomy. Cancer 2006; 107:1440-7.

33. Contant CM, van Geel AN, van der Holt B, Griep C, Tjong Joe Wai R, Wiggers T. Morbidity of immediate breast reconstruction (IBR) after mastectomy by a subpectorally placed silicone prosthesis: the adverse effect of radiotherapy. Eur $J$ Surg Oncol 2000; 26:344-50.

34. Lin KY, Johns FR, Gibson J, Long M, Drake DB, Moore MM. An outcome study of breast reconstruction: presurgical identification of risk factors for complications. Ann Surg Oncol 2001; 8:586-91.

35. Zion SM, Slezak JM, Sellers TA, et al. Reoperations after prophylactic mastectomy with or without implant reconstruction. Cancer 2003; 98:2152-60.

36. Barton MB, West CN, Liu IL, et al. Complications following bilateral prophylactic mastectomy. J Natl Cancer Inst Monogr 2005;61-6. 